


\title{
AVALIAÇÁO DA CAPACIDADE DE RETENÇÃO DE CHUMBO, CRÓMIO, MANGANÊS E NÍQUEL PELO SOLO EM ÁREA DE IMPLANTAÇÁO DE ESTRUTURAS COMPENSATÓRIAS DE DRENAGEM URBANA (BELO HORIZONTE, MG - BRASIL)
}

\author{
EVALUATION OF THE ABILITY TO RETENTION OF LEAD, \\ CHROMIUN, MANGANESE AND NICKEL IN THE SOIL OF THE \\ AREA OF IMPLEMENTATION OF COMPENSATORY URBAN \\ DRAINAGE STRUCTURES (BELO HORIZONTE, MG - BRAZIL)
}

F. M. Belotti ${ }^{1}$, C. V. Oliveira² \& L. Campos ${ }^{3}$

\begin{abstract}
Resumo - O emprego de estruturas compensatórias de drenagem (trincheiras de infiltração, pavimento poroso, entre outras) tem sido apontado como uma alternativa na redução do volume e vazão das cheias urbanas, no aumento da infiltração e na recarga de águas subterrâneas. Entretanto, a infiltração de águas pluviais urbanas com elevado teor de poluentes no solo pode representar um risco de contaminação das águas subterrâneas em virtude da possibilidade de percolação dos mesmos pelo solo. Para avaliar os riscos de lixiviação de metais pesados em uma área de implantação de estruturas de infiltração em Belo Horizonte (Brasil) foram realizadas três amostragens de solo entre março de 2008 e abril de 2009. As amostras coletadas foram submetidas às análises de granulometria, Capacidade de Troca de Cátions, $\mathrm{pH}$ em $\mathrm{H}_{2} \mathrm{O}$ e em $\mathrm{KCl}$, teor de matéria orgânica, teor de Argila Dispersa em Água, mineralogia da fração argila e teor total dos metais chumbo, crómio, manganês e níquel. Os resultados indicam que o solo da área apresenta capacidade para reter parte dos metais oriundos das águas de drenagem urbana; principalmente chumbo, crómio e manganês. Entretanto, outra parte desses metais (principalmente o níquel) pode ser lixiviada no solo, o que evidencia os riscos de contaminação das águas subterrâneas na área

${ }^{1}$ Dep. Engenharia Ambiental, Universidade Federal de Itajubá, Campus Itabira, Minas Gerais, Brasil; fernandabelotti@unifei.edu.br

${ }^{2}$ Dep. Geografia, Instituto de Geociências da Universidade Federal de Minas Gerais, Minas Gerais, Brasil; crisval_oliveira@yahoo.com.br

${ }^{3}$ Dep. Geologia, Escola de Minas da Universidade Federal de Ouro Preto, Minas Gerais, Brasil; lauralfch@gmail.com
\end{abstract}


de implantação das estruturas de infiltração e a necessidade de realizar avaliaçôes específicas sobre a capacidade de retenção de poluentes pelo solo antes da implantação das mesmas.

Palavras-chave - Drenagem urbana; Metais pesados; Estruturas de infiltração; Capacidade de adsorção do solo

Abstract - The employment of structures to compensate for drainage (infiltration trenches, porous pavement, etc.) have been considered as an alternative to reduce the volume and flow of urban flooding, increased infiltration and groundwater recharge. However, the infiltration of urban stormwater with high levels of pollutants in soil may pose a risk of groundwater contamination due to the possibility of percolation of those pollutants by the soil. To evaluate the risks of leaching of heavy metals in an area of implementation of infiltration structures in Belo Horizonte-Brazil three soil samples were collected between March 2008 and April 2009. The samples were analyzed for particle size, Cation Exchange Capacity (CEC), pH in $\mathrm{H}_{2} \mathrm{O}$ and in $\mathrm{KCl}$, organic matter content, content of Clay Dispersed in Water (CDW), clay mineralogy and total content of metals lead, chromium, manganese and nickel. The results indicate that the soil of the area has the capacity to retain some of the metals from the waters of urban drainage mainly lead, chromium and manganese. However, another part of these metals (especially nickel) can be leached into the soil, which demonstrates the risks of contamination of groundwater in the area of implantation of infiltration structures and the need for specific assessments on the retention capacity of pollutants by soil prior to implantation thereof.

Keywords - Urban drainage; Heavy metals; Structures of infiltration; Adsorption capacity of the soil

\section{1 - Introduçáo}

As questóes relacionadas com a drenagem das águas pluviais em áreas urbanas têm adquirido cada vez mais importância, principalmente tendo em vista o aumento do escoamento superficial decorrente da urbanização e a consequente ocorrência de enchentes, responsáveis por uma série de impactos sociais, econômicos e ambientais, cada vez mais significativos (ARAÚJO et al., 2000; TUCCI, 2007).

A frequência de enchentes nas grandes cidades torna urgente a definição e o emprego de um manejo adequado e gestão eficaz das águas pluviais urbanas, buscando formas alternativas de drenagem destas águas, na tentativa de diminuir a magnitude de seu fluxo e reduzir as cheias urbanas (UNESCO, WMO \& IAEA, 2006; TUCCI, 2000).

Nesse sentido, o emprego de estruturas alternativas ou compensatórias de drenagem (trincheiras de infiltração, pavimento poroso, reservatórios de detenção, dentre outras) apresenta-se como um importante instrumento de controle do escoamento superficial, uma vez que tais estruturas buscam reter e infiltrar parcela da água da chuva, o que reduz os volumes escoados e as vazóes máximas de cheias, diminuindo os riscos de inundação e favorecendo a recarga de água subsuperficial (ARAÚJO et al., 2000).

Entretanto, como as águas de drenagem urbana podem conter significativa quantidade de poluentes ambientais, especialmente metais pesados, há a necessidade de investigar a capacidade de retenção do solo na área de implantação das estruturas compensatórias como 
forma de garantir a adsorção dos metais adicionados e o uso adequado da capacidade natural de filtração dos solos (PITT et al., 1994), buscando reduzir os riscos de contaminação das águas subterrâneas e superficiais pela lixiviação de metais na área de implantação destas estruturas.

O objetivo deste trabalho é avaliar a capacidade de retenção de chumbo, crómio, manganês e níquel pelo solo em uma área de instalação de estruturas de infiltração para águas pluviais urbanas em Belo Horizonte, MG - Brasil, e os riscos de contaminação de águas subterrâneas associados à infiltração de águas de drenagem urbana no solo; bem como indicar quais características físicas, químicas e mineralógicas dos solos que mais influenciam na retenção dos metais selecionados, o que pode servir de subsídio para a escolha de locais de implantaçáo para estruturas compensatórias de drenagem.

\section{2 - Metodologia}

\section{1 - Implantação das estruturas de infiltração}

O trabalho foi realizado em uma área de implantação de estruturas de infiltração - uma trincheira de infiltração e uma vala de detenção - para águas pluviais urbanas em Belo Horizonte, estado de Minas Gerais, Brasil, como estudo piloto para testar novas formas de gerenciamento das águas pluviais urbanas no município, dentro do contexto do Projeto SWITCH - Sustainable Water Management Improves Tomorrow's Cities'Health (IHE/UNESCO).

O experimento é composto por uma trincheira de infiltração com $20 \mathrm{~m}$ de comprimento, $1 \mathrm{~m}$ de largura, 1,50 m de altura (profundidade) média, recoberta por manta geotêxtil e preenchida por brita; e uma vala de detenção de $12 \mathrm{~m}$ de comprimento, 3 $\mathrm{m}$ de largura de topo, 1,5 $\mathrm{m}$ de altura (profundidade) e $45^{\circ}$ de declividade dos taludes, recoberta por gramíneas. $\mathrm{O}$ experimento foi instalado em área com declividade de 4,5\%; condutividade hidráulica média do solo de $\mathrm{k}=5,21 \times 10^{-5} \mathrm{~m} / \mathrm{s}$ e profundidade do $\mathrm{N}$. A. (Nível d'Água) maior que 4 metros e as estruturas (trincheira de infiltração e vala de detenção) entraram em funcionamento em maio de 2008.

A área do experimento recebe escoamentos superficiais provenientes da Av. Presidente Carlos Luz, via que liga a área central de Belo Horizonte à região Norte da cidade. A área de contribuição aos dispositivos experimentais, com $3.880 \mathrm{~m}^{2}$, corresponde às três pistas da avenida, incluindo calçadas e passeio. $\mathrm{O}$ escoamento gerado nessa área é drenado por sarjetas até uma boca de lobo, onde é coletado e conduzido até a área do experimento. O volume de escoamento superficial coletado depende da eficiência de captaçáo da boca de lobo, que varia com a vazão afluente, podendo atingir 50 l/s. Uma caixa de passagem permite a divisão dos escoamentos afluentes em duas partes, de forma a alimentar, simultaneamente, a trincheira de infiltração e a vala de detenção. As vazóes afluentes são monitoradas por meio de calhas Parshall implantadas no circuito de alimentação de cada dispositivo.

\section{2 - Amostragem e análises de solo}

Para a realização do monitoramento de retenção de metais pesados foram realizadas três amostragens de solo na área: uma amostragem em março de 2008 (realizada 
antes do funcionamento das estruturas), utilizada para a caracterização física, química e mineralógica do solo da área estudada; uma amostragem em janeiro de 2009 (metade do período chuvoso na área) e uma amostragem em abril de 2009 (fim do período chuvoso).

Foram coletadas amostras na trincheira de infiltração e na vala de detenção em três profundidades: $0-10 \mathrm{~cm} ; 50-60 \mathrm{~cm}$ e $1,00-1,10 \mathrm{~m}$; totalizando seis amostras que foram submetidas a análises físicas, químicas e mineralógicas para definição de sua granulometria, teor de Argila Dispersa em Água (ADA), teor de matéria orgânica, Capacidade de Troca de Cátions (CTC), pH em $\mathrm{H}_{2} \mathrm{O}$ e pH em $\mathrm{KCl}$, mineralogia da fração argila e teor total dos metais $(\mathrm{Pb}, \mathrm{Cr}, \mathrm{Mn}$ e $\mathrm{Ni})$.

As análises de granulometria, $\mathrm{pH}$ em $\mathrm{H}_{2} \mathrm{O}$ e em $\mathrm{KCl}$, CTC e ADA foram realizadas de acordo com EMBRAPA (1997). A análise do teor de matéria orgânica de acordo com o método Walkley-Black (DEFELIPO \& RIBEIRO, 1997). A mineralogia da fração argila por difratometria de raios-X (pelo método do pó) e o teor de metais pesados por ICP-MS (Inductively Coupled Plasma Mass Spectroscopy) de acordo com o método USEPA 3050B.

Os metais a serem analisados foram escolhidos com base em revisão bibliográfica sobre qualidade da água de drenagem urbana em áreas de intenso tráfego de veículos (característica da área de localização das estruturas), que apontou os metais chumbo, crómio, níquel e manganês como os parâmetros mais recorrentes na literatura.

\section{3 - Resultados e discussão}

O solo da área de estudo foi classificado como Cambissolo com textura predominantemente arenosa, elevada variação nos teores de Argila Dispersa em Água (ADA) nos pontos amostrados, mineralogia da fração argila composta por caulinite, gibbsite e goetite, baixa Capacidade de Troca de Cátions (CTC), baixo teor de matéria orgânica e predomínio de cargas negativas ( $\mathrm{pH}$ do solo acima do Ponto de Carga Zero - PCZ) (Tabelas 1 e 2).

Tabela 1 - Características físicas e mineralógicas do solo da área de estudo

\begin{tabular}{|c|c|c|c|c|c|}
\hline \multirow{2}{*}{$\begin{array}{l}\text { AMOSTRA } \\
(\mathrm{cm})\end{array}$} & \multicolumn{3}{|c|}{ Análise textural (g/kg) } & \multirow{2}{*}{$\begin{array}{l}\mathrm{ADA}(\mathrm{g} / \mathrm{kg}) \\
\text { (inicial/final) }\end{array}$} & \multirow[t]{2}{*}{ Mineralogia da fração argila } \\
\hline & areia & silte & argila & & \\
\hline \multicolumn{6}{|l|}{ Trincheira } \\
\hline $0-10$ & 509 & 154 & 337 & 007/102 & caulinite>gibbsite> goetite \\
\hline $50-60$ & 433 & 183 & 384 & $002 / 046$ & caulinite $>$ gibbsite $>$ goetite \\
\hline $100-110$ & 432 & 164 & 404 & $000 / 002$ & caulinite $>$ gibbsite $>$ goetite \\
\hline \multicolumn{6}{|l|}{ Vala } \\
\hline $0-10$ & 495 & 195 & 310 & $252 / 188$ & caulinite $>$ gibbsite $>$ goetite \\
\hline $50-60$ & 374 & 285 & 341 & $001 / 002$ & caulinite $>$ gibbsite $>$ goetite \\
\hline $100-110$ & 421 & 405 & 174 & $004 / 001$ & caulinite>gibbsite> goetite \\
\hline
\end{tabular}


Tabela 2 - Características químicas do solo da área de estudo.

\begin{tabular}{|c|c|c|c|c|c|c|c|c|}
\hline $\begin{array}{c}\text { AMOSTRA } \\
(\mathrm{cm})\end{array}$ & & $\begin{array}{c}\mathrm{pH} \mathrm{em} \\
\mathrm{H} 2 \mathrm{O}\end{array}$ & $\begin{array}{c}\mathrm{pH} \text { em } \\
\mathrm{KCl}\end{array}$ & $\Delta \mathrm{pH}$ & PCZ & $\begin{array}{l}\text { M.O. } \\
(\mathrm{g} / \mathrm{kg})\end{array}$ & CTC & $\begin{array}{l}\text { CTC } \\
\text { efetiva }\end{array}$ \\
\hline \multicolumn{9}{|l|}{ Trincheira } \\
\hline \multirow[t]{2}{*}{$0-10$} & inicial & 5,3 & 4,5 & $-0,8$ & 3,7 & 17 & 2,59 & 1,18 \\
\hline & final & 7,6 & 6,7 & $-0,9$ & 5,8 & 19 & - & - \\
\hline \multirow[t]{2}{*}{$50-60$} & inicial & 5,4 & 4,5 & $-0,9$ & 3,6 & 18 & 2,40 & 1,04 \\
\hline & final & 7,5 & 6,8 & $-.0,7$ & 6,1 & 14 & - & - \\
\hline \multirow[t]{2}{*}{$100-110$} & inicial & 5,4 & 4,5 & $-0,9$ & 3,6 & 18 & 2,37 & 0,66 \\
\hline & final & 7,4 & 6,6 & $-0,8$ & 5,8 & 15 & - & - \\
\hline \multicolumn{9}{|l|}{ Vala } \\
\hline \multirow[t]{2}{*}{$0-10$} & inicial & 7,8 & 7,0 & $-0,8$ & 6,2 & 19 & 4,46 & 3,74 \\
\hline & final & 8,2 & 7,9 & $-0,3$ & 7,6 & 20 & - & - \\
\hline \multirow[t]{2}{*}{$50-60$} & inicial & 6,5 & 5,8 & $-0,7$ & 5,1 & 16 & 3,65 & 2,54 \\
\hline & final & 7,7 & 6,8 & $-0,9$ & 5,9 & 05 & - & - \\
\hline \multirow[t]{2}{*}{$100-110$} & inicial & 6,3 & 5,5 & $-0,8$ & 4,7 & 09 & 3,13 & 2,31 \\
\hline & final & 7,4 & 6,6 & $-0,8$ & 5,8 & 07 & - & - \\
\hline
\end{tabular}

Os teores de metais retidos no solo durante o monitoramento na área de implantação das estruturas de infiltração são apresentados na tabela 3.

Os dados do monitoramento indicam que o solo da área apresenta capacidade de retenção dos metais estudados, principalmente chumbo, crómio e manganês, elementos que apresentaram maiores teores no solo na amostragem realizada na metade do período chuvoso em comparação com os teores existentes no solo no início de funcionamento das estruturas (Tabela 3). Entretanto, dados da amostragem realizada no final do período chuvoso revelam teores de metais menores que aqueles encontrados na amostragem anterior, indicando que parte dos metais adsorvidos durante a primeira metade do período chuvoso foi lixiviada no solo pelas chuvas ocorridas no restante do período (Tabela 3).

Tabela 3 - Teores de metais no solo durante o monitoramento de retenção.

\begin{tabular}{|c|c|c|c|c|c|c|c|}
\hline \multirow[t]{2}{*}{ METAL } & & \multicolumn{3}{|c|}{$\begin{array}{l}\text { Amostragens na trincheira } \\
\qquad(\mathrm{mg} / \mathrm{kg})\end{array}$} & \multicolumn{3}{|c|}{$\begin{array}{c}\text { Amostragens na vala } \\
(\mathrm{mg} / \mathrm{kg})\end{array}$} \\
\hline & & $1^{\mathrm{a}}$ & $2^{a}$ & $3^{\mathrm{a}}$ & $1^{a}$ & $2^{a}$ & $3^{a}$ \\
\hline \multirow{3}{*}{ Chumbo } & $0-10$ & 5,86 & 7,95 & 8,04 & 4,98 & 8,46 & 10,62 \\
\hline & $50-60$ & 6,25 & 8,02 & 8,00 & 4,12 & 7,52 & 7,48 \\
\hline & $100-110$ & 6,26 & 7,36 & 6,89 & 7,37 & 8,88 & 7,79 \\
\hline \multirow{3}{*}{ Crómio } & $0-10$ & 11,35 & 9,67 & 6,59 & 9,05 & 15,00 & 22,28 \\
\hline & $50-60$ & 11,43 & 20,72 & 6,63 & 8,69 & 9,81 & 6,06 \\
\hline & $100-110$ & 17,54 & 11,79 & 8,71 & 7,41 & 11,11 & 6,39 \\
\hline
\end{tabular}




\begin{tabular}{cccccccc} 
& $0-10$ & 16,36 & 19,94 & 12,01 & 18,19 & 176,32 & 247,56 \\
\multirow{2}{*}{ Manganês } & $50-60$ & 16,70 & 23,18 & 11,97 & 7,15 & 33,14 & 11,30 \\
& $100-110$ & 12,19 & 26,55 & 14,32 & 13,39 & 17,66 & 15,27
\end{tabular}

$\begin{array}{cccccccc}\text { Níquel } & 0-10 & 1,34 & 1,99 & 0,71 & 2,18 & 3,86 & 3,73 \\ & 50-60 & 1,40 & 2,25 & 0,71 & 1,04 & 2,07 & 0,67 \\ & 100-110 & 1,46 & 2,70 & 0,94 & 0,84 & 1,84 & 0,83\end{array}$

$1^{\text {a }}$ amostragem - março de 2008 (implantaçấo das estruturas), $2^{\text {a }}$ amostragem - janeiro de 2009 (metade do período chuvoso na área), $3^{\mathrm{a}}$ amostragem - abril de 2009 (final do período chuvoso na área).

O chumbo foi o metal mais fortemente adsorvido pelo solo, com retenção também na $3^{a}$ amostragem. O metal foi retido em todos os pontos amostrados na $2^{a}$ amostragem, e apresentou aumento dos seus teores no solo ou apenas uma ligeira redução na amostragem realizada no final do período chuvoso. A capacidade de retençáo do chumbo pelo solo da área pode ser explicada pela elevada afinidade deste elemento com óxidos de ferro, formando ligaçóes mais estáveis, o que reduz a sua mobilidade e lixiviação no perfil do solo (ARAÚJO et al., 2002).

A semelhança nas taxas de adsorção em todos os pontos amostrados pode também ser correlacionada com o papel dos óxidos de ferro na retençáo de chumbo, uma vez que o tipo e o teor de óxidos sáo basicamente o mesmo em todos os pontos amostrados.

Destacam-se os pontos $0-10 \mathrm{~cm}$ e $50-60 \mathrm{~cm}$ na trincheira e o ponto $50-60 \mathrm{~cm}$ na vala em virtude da manutenção de praticamente o mesmo teor do metal da metade ao final do período chuvoso, o que pode indicar a saturação do solo nestes pontos, onde não é mais possível a retenção de metais.

$\mathrm{O}$ aumento do $\mathrm{pH}$ durante o monitoramento também pode ter contribuído para a adsorção de chumbo, devido à diminuição da concentração de $\mathrm{H}^{+}$e ao aumento das cargas negativas devido à desprotonação de grupos $\mathrm{OH}^{-}$. Com o aumento do $\mathrm{pH}$, a concentração de íons hidrogênio diminuiu, possibilitando um aumento da adsorção de cátions metálicos (PIERANGELI et al., 2001).

O crómio não apresentou comportamento homogêneo nos diversos pontos estudados, manifestando-se de três maneiras: i) redução dos teores do início ao fim do monitoramento nos pontos T1 (trincheira 0-10 cm) e T3 (trincheira 50-60 cm); ii) aumento dos teores da $1^{\text {a }}$ para a $2^{\text {a }}$ amostragem nos demais pontos estudados e iii) redução dos valores da $2^{a}$ para a $3^{a}$ amostragem, exceto no ponto V1 (vala $0-10$ $\mathrm{cm})$. Destaca-se o aumento significativo dos teores da $1^{\text {a }}$ amostragem $(11,43 \mathrm{mg} /$ $\mathrm{kg})$ para a $2^{\text {a }}$ amostragem $(20,72 \mathrm{mg} / \mathrm{kg})$ na trincheira à profundidade $50-60 \mathrm{~cm}$, acompanhado de redução significativa da $2^{\text {a }}(20,72 \mathrm{mg} / \mathrm{kg})$ para a $3^{\mathrm{a}}$ amostragem $(6,63 \mathrm{mg} / \mathrm{kg})$.

O comportamento do crómio na área apresenta-se em desacordo com a literatura, que diz que este metal, assim como o chumbo, possui a tendência de se ligar mais fortemente aos solos, através de mecanismos de adsorção interna, ou seja, ligaçóes fortes que limitam a sua dessorção e liberação para a solução do solo (ARAÚJO et al., 2002), sendo normalmente, pouco móvel nos solos. 
Os resultados da $3^{a}$ amostragem (final do período chuvoso) indicam que a água que se infiltra nas estruturas não só lixiviou o crómio que foi retido no solo durante a primeira metade do período chuvoso, como também lixiviou parte do crómio já existente no solo quando da implantaçáo do experimento. Provavelmente, esse efeito pode ser atribuído à retenção do metal em frações mais móveis, ligado a sítios não-específicos, cedendo lugar a elementos com maior afinidade pela matriz do solo ou a sua ligação à fração argila dispersa do solo, que apresenta valores elevados em diversos pontos de amostragem, o que pode ter contribuído para o transporte de crómio através da movimentação da argila.

$\mathrm{O}$ aumento do $\mathrm{pH}$ da $1^{\mathrm{a}}$ para a $3^{\mathrm{a}}$ amostragem pode ter favorecido a complexação do crómio pela matéria orgânica dissolvida, uma vez que o $\mathrm{pH}$ elevado favorece a complexação crescente de alguns cátions por ligantes dissolvidos, o que aumenta a mobilidade do metal (GUILHERME et al., 2005; KLITZKE et al., 2008).

A elevada retenção de crómio na vala à profundidade de $0-10 \mathrm{~cm}$ pode provavelmente ser explicada pelo efeito de sedimentaçấo dos sólidos suspensos dissolvidos das águas de drenagem urbana, comportamento observado para os demais metais estudados.

O manganês apresentou elevadas taxas de retenção do início do monitoramento até a metade do período chuvoso, com maiores valores na vala à profundidade de $0-10 \mathrm{~cm}$. Entretanto, houve redução dos seus teores no solo da 2a (metade do período chuvoso) para a $3^{\mathrm{a}}$ amostragem (final do período chuvoso), exceto no ponto $0-10 \mathrm{~cm}$ na vala, no qual houve aumento no teor retido.

O comportamento do manganês parece estar diretamente relacionado ao teor de matéria orgânica. $\mathrm{O}$ registro de maior retenção foi na vala à profundidade de $0-10 \mathrm{~cm}$, apresentando este ponto, elevação significativa do teor de matéria orgânica do início ao fim do monitoramento. Na vala à profundidade de $50-60 \mathrm{~cm}$, a redução dos teores de matéria orgânica de 1,6 para $0,5 \%$ durante o monitoramento pode justificar os teores lixiviados que foram os maiores dentre os pontos amostrados.

O níquel apresentou retenção da $1^{a}$ para a $2^{a}$ amostragem e significativa redução nos seus valores (em média redução de $50 \%$ no teor da $2^{\text {a }}$ para a $3^{\text {a }}$ amostragem, exceto para a vala à profundidade de $010 \mathrm{~cm}$ ), sendo que em quatro dos nove pontos amostrados (nas três amostras coletadas na trincheira e na amostra de $50-60 \mathrm{~cm}$ coletada na vala), os teores na $3^{\mathrm{a}}$ amostragem foram menores que aqueles existentes no solo antes do início do monitoramento. Os reduzidos valores de retenção e a significativa perda de níquel da metade para o final do período chuvoso evidenciam o reduzido poder de competição deste elemento em relaçáo aos demais e concorda com KRETZSCHMAR \& VOEGELIN (2001) e ZEHETNER \& WENZEL (2000), segundo os quais a retenção de níquel em solos é bastante reduzida quando este compete com outros metais.

A reduzida retençâo pode ser explicada pelo menor poder de competição do níquel com outros metais pelos sítios de adsorçáo do solo; enquanto que as elevadas taxas de lixiviação podem ser atribuídas aos aportes de água pluvial nos meses de intervalo entre as amostragens, com novas entradas de metais no solo, capazes de deslocar o níquel adsorvido anteriormente.

Outro fator que afeta as taxas de retenção é o elevado teor de $\mathrm{Ca}^{++}$no solo. De acordo com ZEHETNER \& WENZEL (2000), a adsorção de níquel pelo solo é drasticamente reduzida e o transporte através dos solos é significativamente aumentado na presença de cálcio; efeitos atribuídos à competição entre cálcio e níquel nas regiôes trocáveis na superfície do solo. 
De forma geral, cinco características do solo podem ser utilizadas para explicar as taxas de adsorção e lixiviação dos metais na área:

i) a reduzida Capacidade de Troca de Cátions (CTC) e o reduzido teor de matéria orgânica, que limitam a adsorção dos metais com afinidades para esses sítios, sejam eles o níquel ou o manganês;

ii) o elevado teor de Argila Dispersa em Água (ADA) em alguns pontos amostrados, o que pode contribuir para a lixiviação de metais adsorvidos nas argilas;

iii) o aumento do $\mathrm{pH}$ durante o monitoramento, que pode contribuir negativamente na retenção de manganês em razão da afinidade deste elemento pela matéria orgânica solúvel, que tem a sua solubilidade aumentada com o aumento do $\mathrm{pH}$ do solo. Por outro lado, o aumento do $\mathrm{pH}$ favorece a adsorçáo de chumbo, porque aumenta a adsorção de cátions pelos óxidos de ferro (GUILHERME et al., 2005) e aumenta a CTC do solo, favorecendo a retenção de metais nos sítios de troca de cátions;

iv) o elevado teor de $\mathrm{Ca}^{++}$na área de estudo limita a adsorção de metais nos sítios de troca catiônica. Os cátions metálicos competem com $\mathrm{Ca}^{++}$, que tem preferência pelos sítios de troca de cátions nos solos. Entretanto, a retenção do chumbo,

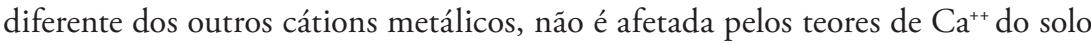
(RIBEIRO-FILHO et al., 2001);

v) a presença de óxidos de ferro e alumínio no solo, que contribuem para a retençáo e manutenção de metais com afinidade por estes óxidos, principalmente o chumbo, fazendo com que ele seja o elemento menos lixiviado na área de implantação das estruturas.

Dentre os pontos amostrados, destaca-se o comportamento diferenciado do ponto vala $0-10 \mathrm{~cm}$, que apresentou elevados teores de retenção para todos os elementos estudados, o que pode, provavelmente, ser explicado pelo efeito de sedimentação de partículas no fundo da vala de detenção. Grande parte dos metais depositados nas ruas no período seco associam-se às partículas finas, sendo posteriormente carreados pela enxurrada na fração de sólidos suspensos (HOFFMAN et al., 2002). Como a vala exerce o papel de decantação, comum em estruturas de detenção, pode haver a sedimentação das partículas finas, enquanto que a água se infiltra no solo. $\mathrm{O}$ material em suspensão é retido por filtração/sedimentação (precipitação), enquanto que o material dissolvido pode ser adsorvido no solo.

O efeito de sedimentação de partículas que ocorre na vala não é verificado na trincheira, devido ao recobrimento desta estrutura com uma manta geotêxtil, o que faz com que os metais da fração sólidos suspensos advindos na água de escoamento fiquem retidos nesta manta.

Dentre os fatores que afetaram o comportamento dos metais no solo, a competiçáo entre eles também tem efeito importante, tendo em vista a presença de diversos metais nas águas pluviais urbanas.

No estudo de adsorção competitiva com $\mathrm{Cr}, \mathrm{Ni}, \mathrm{Cu}, \mathrm{Zn}, \mathrm{Cd}$ e Pb, (FONTES \& GOMES, 2003) constataram que quase todos os metais foram adsorvidos pelo solo em concentraçóes mais baixas, ocupando uma percentagem proporcional relativa à sua concentração molar na solução. Contudo, quando a concentração aumentou, alguns 
competidores mais fortes, como o $\mathrm{Cr}, \mathrm{Cu}$ e $\mathrm{Pb}$ mantiveram a sua forte afinidade com a superfície adsorvedora, enquanto outros competidores mais fracos, como $\mathrm{Ni}, \mathrm{Zn}$ e $\mathrm{Cd}$, foram deslocados, reduzindo, portanto, as suas quantidades adsorvidas.

\section{4 - Conclusóes}

A análise e interpretação dos dados permite concluir que o solo da área de estudo possui capacidade para reter parte dos metais existentes nas águas de drenagem urbana que infiltram nas estruturas. Entretanto, outra parte desses metais é lixiviada ao longo do perfil do solo, o que representa um risco efetivo de contaminação das águas subterrâneas pela infiltração de águas de drenagem urbana nas estruturas de compensação em Belo Horizonte-Brasil.

O aporte constante de metais através da infiltração de águas pluviais na área pode fazer com que os sítios de adsorção do solo se tornem saturados, deixando parte dos metais presentes nas águas pluviais disponíveis em solução e passíveis de serem carreados no perfil do solo.

Os resultados evidenciam a importância e a necessidade de incorporar a capacidade de retenção de poluentes pelo solo como mais um critério a ser avaliado na escolha de áreas para a implantação de estruturas de infiltração para águas pluviais urbanas. De maneira geral, solos com elevado teor de Argila Dispersa em Água (ADA), baixo teor de matéria orgânica, baixa Capacidade de Troca de Cátions (CTC) e baixo teor de óxidos de ferro e alumínio não devem ser utilizados para implantação dessas estruturas.

Agradecimentos - Ao Projeto Sustainable Water Management Improves Tomorrow's Cities' Health - SWITCH (Institute for Water Education - IHE/UNESCO), pelo custeio parcial das análises de solo e à Fundação de Amparo à Pesquisa de Minas Gerais - FAPEMIG pela concessão de bolsa de estudo à primeira autora.

\section{Referências Bibliográficas}

ARAÚJO, P. R., TUCCI, C. E. M. \& GOLDENFUN, J. A. (2000) - Avaliação da Eficiência dos Pavimentos Permeáveis na Reduçấo do Escoamento Superficial. Rev. Bras. Rec. Hídricos, 3, p. 21-29.

ARAÚJO, W. S., AMARAL SOBRINHO, N. M. B., MAZUR, N. \& GOMES, P. C. (2002) - Relação entre adsorção de metais pesados e atributos químicos e físicos de classes de solos do Brasil. Rev. Bras. Ci. Solo, 26, p. 17-27.

DEFELIPO, B. V. \& RIBEIRO, A. C. (1997) - Análise química do solo. Boletim de extensão, 29UFV, 26 p.

EMBRAPA (1997) - Empresa Brasileira de Pesquisa Agropecuária. Centro Nacional de Pesquisa de Solos - Manual de Métodos de Análise de Solo, 212 p.

FONTES, M. P. F. \& GOMES, P. C. (2003) - Simultaneous competitive adsorption of heavy metals by the mineral matrix of tropical soils. Appl. Geochem., 18, p. 795-804.

GUilherme, L. R. G., MARQues, J. J., Pierangeli, M. A. P., ZUliAni, D. Q., CAMPOS, M. L. \& MARCH, G. (2005) - Elementos-traço em Solos e Sistemas Aquáticos. Tópicos Ci. Solo, 4, p. 345-390.

HOFFMAN, D., RATTNER, B., BURTON Jr. G. A. \& CAIRNS Jr. J. (2002) - Handbook of ecotoxicology. In: Hoffman, D., Rattner, B., Burton, Jr., G. \& Cairns Jr., J. (eds.). HCRC-Lewis, Boca Raton, 1290p. 
KLITZKE, S., LANG, F. \& KAUPENJOHANN, M. (2008) - Increasing pH releases colloidal lead in a highly contaminated forest soil. Eur. J. Soil Sci., p. 265-273.

KRETZSCHMAR, R. \& VOEGELIN, A. (2001) - Modeling Competitive Sorption and Release of Heavy Metals in Soils. In: SELIM, H. M; SPARKS, D. L. (eds.). Heavy Metals Release in Soils. CRC Press, Boca Raton, p. 55-88.

PIERANGELI, M. A. P., GUILHERME, L. R. G., CURI, N., SILVA, M. L. N., OLIVEIRA, L. R. \& LiMA, J. M. (2001) - Teor total e capacidade máxima de adsorção de chumbo em Latossolos Brasileiros. Rev. Bras. Ci. Solo, 25, p. 279-288.

PITT, R., CLARK, S. \& PARMER, K. (1994) - Potential Groundwater Contamination from Intentional and Nonintentional Stormwater Infiltration. EPA (Environmental Protection Agency), p. 1-7.

RIBEIRO-FILHO, M. R., SIQUEIRA, J. O., CURI, N. \& SIMÃO, J. B. P. (2001) - Fracionamento e biodisponibilidade de metais pesados em solo contaminado, incubado com materiais orgânicos e inorgânicos. R. Bras. Ci. Solo, Viçosa, 25, p. 495-507.

TUCCI, C. E. M. (2000) - Coeficiente de Escoamento e Vazão Máxima de Bacias Urbanas. Rev. Bras. Rec. Hidricos, 1, p. 61-68.

TUCCI, C. E. M. (2007) - Impactos da urbanização. In: Tucci, C. E. M. Inundações urbanas. ABRH, Porto Alegre, p. 104-121.

UNITED NATIONS EDUCATIONAL SCIENTIFIC AND CULTURAL ORGANIZATION, WORLD METEOROLOGICAL ORGANIZATIONS \& INTERNATIONAL ATOMIC ENERGY AGENCY. (2006) - The $2^{\text {nd }}$ UN World Water Development Report: "Water, a shared responsibility". http://www. unesco.org/water/wwap/wwdr/wwdr2/table_contents.shtml (consultado em 2009. 08.12).

ZEHETNER, F. \& WENZEL, W. W. (2000) - Nickel and copper sorption in acid forest soils. Soil Science, 165 , p. 463-472. 